\title{
Finding Common Ground For Content And Technology: A Model For Course Development
}

Frank A. Cerreto (E-mail: frank.cerreto@stockton.edu), Richard Stockton College of New Jersey Jung Lee (E-mail: leej@loki.stockton.edu), Richard Stockton College of New Jersey

\begin{abstract}
A mathematics educator and an instructional technologist developed a practical, collaborative model that integrates content and technology and applied this model to a mathematics course for prospective elementary school teachers.
\end{abstract}

\section{Introduction}

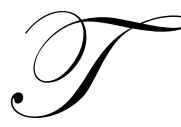

he positive effects of technology are directly attributed to how it is implemented and how educators are instructed to utilize it (Becker, 2000; Becker, Ravitz, \& Wong, 1999; Branch 2000; SIIA, 2000). Teacher education programs are aware of these findings and offer courses teaching how to integrate technology into curriculum. When developing such courses for pre-service teachers, instructors need to consider how to balance and infuse two elements, content and technology, into the curriculum. However, the literature on technology integration does not fully address the issues of balance and interaction between content and technology in the course development process.

Existing courses address technology in two different ways, but both have limitations vis-à-vis the effective integration of technology and content. The first way overemphasizes technology. For example, in order to assist pre-service teachers in incorporating technology into their classes, "teacher preparation programs typically provide a course about (emphasis added) technology, perhaps with a unit or discussion on teaching with technology ... (Niess, 2001, p.103)." The other way overemphasizes content knowledge. In content courses, instructors often attempt to use technology merely as an add-on, once course objectives and tasks have already been established.

In either case, the interaction between these two elements is not fully exploited (Johnson, 1991). As a consequence, pre-service teachers complete their programs without having had experience in integrating content and technology in a seamless and effective manner.

Moreover, teachers teach as they were taught, rather than as they were taught to teach (Jones, 1975). Having experienced learning that benefits from this interaction between content and technology, pre-service teachers will be motivated and prepared to bring this approach to their classrooms.

The curricular problem described above is, in part, a reflection of the widely used models for course development. In most classical instructional design models, the question of how to utilize technology is introduced relatively late in the process (Dick, Carey, L. \& Carey, J., 2001; Seels \& Glasgow, 1998). In particular, technology is generally not considered until objectives have already been articulated and learning tasks are being planned. This approach may restrict the uses of technology to the confines of the previously defined content objectives.

On the other hand, many textbooks on integrating technology into courses for teachers (for example, Heinich, Molenda, Russell \& Smaldino, 2001; Jonassen, 2000; Kemp \& Smellie, 1998) employ models fostering approaches that begin with a discussion of technology tools and the ways they can be used to promote learning and teaching. Then a few examples of how to utilize this technology in different subjects are introduced. This approach 
delays the introduction of content in the planning process. It is unreasonable to expect that teachers will be able to transfer these techniques into their specific subject areas.

We, one mathematics educator and one instructional technologist, tried to resolve the conflict between content and technology by developing a practical, collaborative model that integrates them in a balanced manner. To optimize the interaction between content and technology, we searched for common ground between two, rather than beginning in one area and then having to decide how to fit the other. Academic goals and themes were identified as common ground.

After developing the model, we applied it to the design of a new course, and one of the authors taught the course. The outcomes of this course were evaluated by three main categories of pre and post measures: (1) students' attitudes toward mathematics, (2) technology attitudes and (3) mathematics performance. In this paper, we will illustrate the model, describe its application to a mathematics course for prospective elementary school teachers and discuss students' outcomes, as a case study.

\section{UTAG-ITAC Model}

The course development model is called UTAG-ITAC (Using Themes And Goals to Integrate Technology And Content). First, a needs analysis is conducted. Then, general course goals, not content-specific goals, are established. After this step, the content specialist generates a list of content objectives that address these goals, and the technology specialist determines what available technological tools might be used to promote the goals, carrying out these processes independently. Next, the collaborators decide on a theme or themes that can be used to organize classroom activities. Using each theme as a focus, the two then develop learning activities designed to achieve the content objectives, while remaining cognizant of the goals. Finally, they implement and evaluate the course. Like the standard models, the UTAG-ITAC model contains feedback loops for revision, based on formative evaluation. Figure 1 illustrates the model and the role of content and technology in each of six steps.

\section{Application Of UTAG-ITAC To Teacher Education Course}

The model was implemented at a public, four-year college in the Northeast. The college offers elementary and secondary teacher certification programs that serve both undergraduate and post-baccalaureate students.

\subsection{Step 1: Conduct Needs Analysis}

The needs analysis contains three parts: one for content, one for technology, and one for global considerations. When this model was applied to the specific course development project, the need was defined as the requirement that prospective elementary school teachers deepen their understanding of the mathematics content they will be teaching. Students in the elementary certification program were required to complete one mathematics course and one course in methods of teaching elementary school mathematics.

Faculty members who taught the methods course found that students were extremely underprepared in terms of their own understanding of elementary school mathematics. As a result, students had tremendous difficulty focusing on issues of pedagogy while struggling with the mathematical content.

The technologist recommended that the new course be taught in a computer lab. Software was limited to Internet access, Microsoft Office Suite, and a few other low-end packages. In addition, the technologist determined that students would bring with them only rudimentary technical skills.

\subsection{Step 2: Establish Goals}

The authors discussed both the capacity of technology to promote broad academic goals and the goals of the particular content area. Technology-enhanced courses promote not only students' achievement, but also critical thinking skills, collaboration, higher-order thinking skills, and independent learning skills (Becker, 2000; Heinich, 
Molenda, Russell \& Smaldino, 2001; Jonassen, 2000). The National Council of Teachers of Mathematics (NCTM, 2000) identified five process standards for school mathematics: problem solving, reasoning and proof, communication, connections, and representation. Because of the similarities between these two lists, the collaborators selected the five NCTM process standards as goals, which would serve as common ground.

The problem solving standard demonstrates many of the necessary characteristics of a UTAG-ITAC goal. The goals are, in a sense, trans-academic. That is, they address specific content, but they also transcend it. The set may include both cognitive and meta-cognitive goals, and they will vary from course to course.

Figure 1: UTAG-ITAC Model and Process

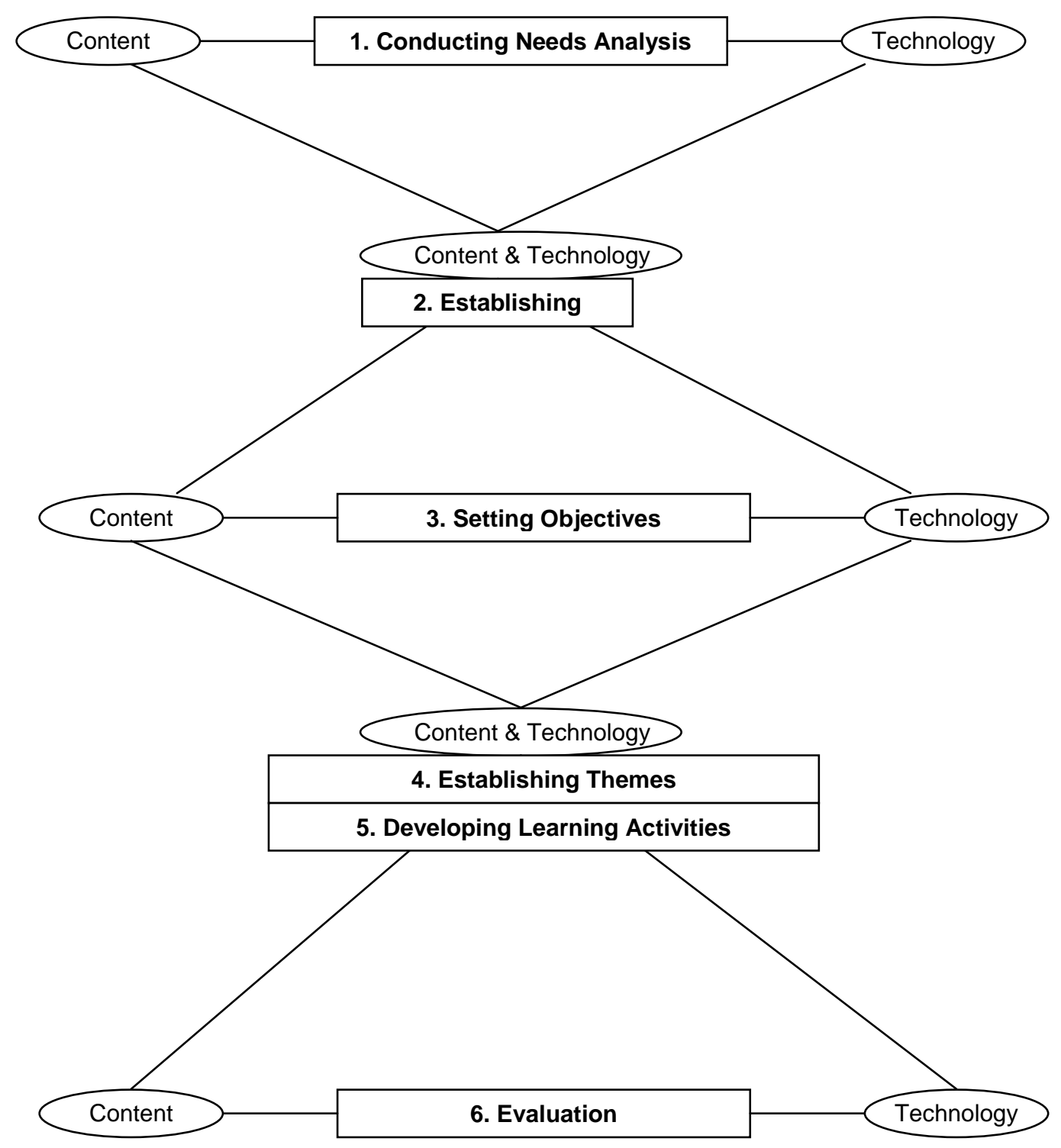




\subsection{Step 3: Set Objectives}

The mathematics educator developed content objectives, and the technologist analyzed available technology tools and the roles they might play. In both cases, they were guided by the common set of course goals. The process is a cyclical one: First, they carry out these processes independently, and then they discuss their work and revise their lists.

\subsection{Step 4: Create Themes}

Having articulated the content objectives and technology tools, we decided on a set of themes for the course that are related to realistic situations and are intended to embed the learning in an authentic context. In addition, along with the goals, they are used to bring together content and technology in a balanced way. A course may use one or several themes, and themes will naturally vary from course to course. For each theme, we developed several situational contexts and articulated the mathematics content that might relate and the technology that might be used.

\subsection{Step 5: Develop Learning Activities}

We developed classroom activities and created several open-ended, small-group projects, based on the themes and goals. Students demonstrate their understanding of the mathematical content by presenting to the class in a multimedia format. In this case, technology serves as a intelligent partner (Jonassen, 2000) and collaboration tool (Jonassen,et al. 2002).

This step captures the synergy that exists among the theme, content, and technology in the learning activities development triad. These three elements interact in a reciprocal manner, as shown in Figure 2.

Figure 2. Learning Activities Development Triad

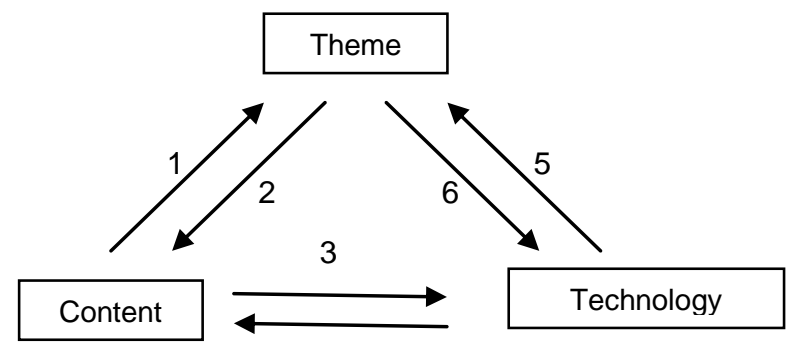

4

1. How can we introduce this objective?

2. What objectives are related to this thematic situation?

3. Here is an importatnt objective to teach. How can technology help?

4. Here is an interesting tool. How can this help acieve content objectives?

5. How can this tool be applied to this thematic situaion?

6. What tools can be used to develop this thematic situation? 
As the figure demonstrates, neither content nor technology is the servant of the other. Rather, they are interdependent with one another as well as with the theme. Like a stool, the learning activities development process requires three legs to stand.

\subsection{Step 6: Implement Instruction And Conduct Evaluation}

The mathematics educator taught this course in the computer lab, with occasional visits by the technology specialist. The technologist served both as an observer and as a technology facilitator. This close collaboration allowed for regular feedback on the instructional program and on-the-fly revision as necessary.

Students were evaluated in a variety of ways, in coordination with the general goals, the specific mathematics objectives, and the technology objectives. Tests and quizzes were designed to assess their understanding of mathematical content and were embedded with the general goals of problem solving, reasoning and proof, connections, and representation. The group projects and presentations also provide insight into students' ability to communicate mathematical ideas in a variety of forms, including written and oral. The presentations also demonstrate their ability to utilize technology effectively. In addition, student journal entries provide other evidence of student progress, including attitudinal shifts.

\section{Results}

During the Spring 2003 semester, two sections of the course were offered $(\mathrm{N}=51)$. In order to determine changes in students' attitude in mathematics and technology, the Fennema-Sherman Mathematics Attitude Survey (MAS) and Teachers' Attitudes Toward Computers Questionnaire (TAC) (Christensen \& Knezek 1998) were administered at the beginning and the end of the semester. To measure students' mathematics performance, teacherconstructed, pre- and post-tests were conducted. On all scores, paired t-test analysis was conducted.

Two of the factors measured in MAS are mathematics usefulness and confidence in mathematics. Usefulness scores were significantly different $(\mathrm{p}<.001)$, with post-test scores higher than pre-test scores, while confidence scores were not significantly different.

In the TAC, three factors were examined, enjoyment, anxiety and productivity. Although scores for enjoyment and anxiety were not significantly different, productivity scores were significantly improved $(\mathrm{p}<.005)$. $(\mathrm{p}<.005)$.

On the teacher-made math performance test, post-test scores were significantly higher than pre-test scores

\section{Discussion}

Effectively integrating content and technology presents a formidable challenge, with one of the two elements inevitably reduced to the role of servant. We developed the UTAG-ITAC model because of our dissatisfaction with existing course development models where technology should play an integral role. In this model, content and technology stand on equal footing in the course development process. Setting general goals that transcend content and technology provides the common ground for deciding what is to be taught. Using a real-life theme as the medium for developing activities provides the common ground for deciding how it is to be taught. The case study demonstrates that this model can work, with close collaboration between the content and technology specialists.

Applying the UTAG-ITAC model to course development not only serves as an innovative way to integrate technology and content, but also enables an interesting, reciprocal interaction between these two elements. Not only does technology respond to content, as would be expected, but it is also theoretically possible that content might respond to technology. Further use of this model should reveal whether significant responses of content to technology do in fact occur. 
The model has a few practical limitations, though. The teacher may have limited access to a technology specialist or limited knowledge of technology. The technology specialist may not have instructional design experience. The institution may have limited hardware and software resources.

While the UTAG-ITAC model holds promise as a course development approach, this model is still in its developmental stage and has been applied to only one course. In the absence of controlled, experimental conditions, no cause-and-effect relationship can be posited at this time. Moreover, many questions remain. How well will the model work in other courses (subject, level, etc.)? How might the model be adapted to the redesign of existing courses?

\section{References}

1. Becker, H. J. (2000). "Pedagogical motivations for student computer use that lead to student engagement", Educational Technology, 40(5), 5-17.

2. Becker, H. J., Ravitz, J. \& Wong, Y. (1999). "Teacher and teacher-directed student use of computers and software", http://www.crito.uci.edu/tlc/findings/ComputerUse/html/startpage.htm.

3. Branch, A (2000). "Report: 20 years of technology has improved learning in schools", Curriculum Administrator, 36(9), 16-17.

4. Christensen, R. \& Knezek, G. (1998). "Parallel Forms for Measuring Teacher's Attitudes Toward Computers", Proceedings of SITE 98. Association for the Advancement of Computing in Education: Charlotteville, VA, p 831-832

5. Dick, W., Carey, L., \& Carey, J. O. (2000) The Systematic Design of Instruction (5th ed.). Addison-Wesley Publishing.

6. Heinich, R., Molenda M., Russell J. D., \& Smaldino, S. (2001) Instructional Media and Technologies for Learning (7th ed.). Upper Saddle River, NJ: Prentice Hall.

7. Johns, E. (1975). "Providing college-level role models for the socialization of elementary level open classroom teachers", California Journal of Teacher Education, 2, 33-51.

8. Johnson, J. (1991) "Are paradigms worth more than a pair of dimes?", The Computing Teacher, 19(2), $38-40$.

9. Jonassen, D. H. (2000). Computers as Mindtools for Schools: Engaging Critical Thinking (2nd ed.). Upper Saddle River, NJ: Prentice Hall.

10. Kemp, J. E. \& Smellie, D. C. (1998). Planning, Producing, and Using Instructional Media (7th ed.). Boston, MA:Addison-Wesley.

11. National Council of Teachers of Mathematics (NCTM, 2000), Principles and Standards of School Mathematics. Reston, VA: Author.

12. Niess, M. L. (2001). "A model for integrating technology in preservice science and mathematics contentspecific teacher preparation", School Science \& Mathematics, 101(2), 102-110.

13. Seels, B. \& Glasgow Z. (1997) Making Instructional Design Decisions (2nd Edition). Upper Saddle River, NJ: Prentice Hall.

14. Software and Information Industry Association (2000) "Research report on the effectiveness of technology in schools: executive summary", http://www.siia.net/sharedcontent/store/e-edtech-sum00.pdf. 